\title{
Crystallization Induced Dynamic Resolution of Ethyl Thiazolidine-2-Carboxylate
}

\author{
Seung Kyu Kang, Woul Seong Park, T. S. Thopate, and Jin Hee Ahn* \\ Drug Discovery Division, Korea Research Institute of Chemical Technology, Daejeon 305-600, Korea \\ *E-mail: jhahn@krict.re.kr \\ Received June 14, 2010, Accepted July 22, 2010
}

Key Words: Crystallization induced dynamic resolution, Ethyl thiazolidine-2-carboxylate, Tartaric acid

Unnatural amino acids are widely utilized as biological active compounds and synthetic intermediates. Among them, thiazolidine-2-carboxylic acid, which is an unnatural cyclic amino acid, was found in medicinal and organic chemistry area, many of which showed biological activity and used as useful building blocks in organic synthesis. ${ }^{1-7}$

Several approaches for obtaining optically pure thiazolidine2-carboxylic acid derivatives have been reported. Johnson et al. ${ }^{1}$ reported the resolution of racemate of thiazolidine-2-carboxylic acid ester in ethanol and ether medium but yield is ranging between $43-47 \%$. Shiraiwa et al. ${ }^{8}$ synthesized optically active thiazolidine carboxylic acid by asymmetric transformation in acetic acid and ethanol medium using $(+)$ or $(-)$ tartaric acid salt and further hydrolysis of salt in triethylamine and methanol gave only $\sim 50 \%$ optically active thiazolidine carboxylic acid. This prompted us to develop an efficient crystallization induced dynamic resolution for thiazolidine-2-carboxylic acid derivative. Crystallization induced dynamic resolution (CIDR) is an attractive approach for dynamic resolution, in which one of diastereomers crystallizes preferentially with high selectivity. ${ }^{9}$ Among thiazoldine-2-carboxylic acid derivatives, we focused on ethyl thiazolidine-2-carboxylate and herein wish to report the crystallization induced dynamic resolution (CIDR) of racemic ethyl thiazolidine-2-carboxylate.

First, racemic ethyl thiazolidine-2-carboxylate was synthesized by literature method. ${ }^{10}$ In order to investigate the possibility of crystallization induced dynamic resolution, the racemization of optically active $(S)$-ethyl thiazolidine-2-carboxylate · L-tartaric acid (TA) salt in ethanol solution was performed and the results are summarized in Table 1 . At $20^{\circ} \mathrm{C}$, racemization of $99 \%$ de $(S)$-ethyl thiazolidine-2-carboxylate $\cdot$ L-TA salt

Table 1. Racemization of (S)-ethyl thiazolidine-2-carboxylate - L-TA in $\mathrm{EtOH}$

\begin{tabular}{|c|c|c|c|}
\hline \multicolumn{4}{|l|}{$>99$} \\
\hline Entry & Reaction temperature & Reaction time & $\%$ de \\
\hline 1 & $20{ }^{\circ} \mathrm{C}$ & $0 \mathrm{~h}$ & 99 \\
\hline 2 & $20{ }^{\circ} \mathrm{C}$ & $24 \mathrm{~h}$ & 99 \\
\hline 3 & $40{ }^{\circ} \mathrm{C}$ & $3 \mathrm{~h}$ & 82 \\
\hline 4 & $40{ }^{\circ} \mathrm{C}$ & $24 \mathrm{~h}$ & 48 \\
\hline 5 & $80{ }^{\circ} \mathrm{C}$ & $0.5 \mathrm{~h}$ & 0 \\
\hline
\end{tabular}

didn't take place after $24 \mathrm{~h}$ (entry 1-2). Whereas at $40{ }^{\circ} \mathrm{C}$, racemization was slowly occurred (entries 3-4). When the reaction was carried out at $80^{\circ} \mathrm{C}$, compound was rapidly racemized. These results suggested that CIDR process of ethyl thiazolidine-2carboxylate could be possible between $20-80{ }^{\circ} \mathrm{C}$.

We investigate the crystallization induced dynamic resolution to obtain optically active ethyl thiazolidine-2-carboxylate through the formation of optically active salt with L-tartaric acid, as a resolving agent as shown in Scheme 1.

A solution of racemic ethyl thiazolidine-2-carboxylate in ether was mixed with a solution of L-tartaric acid in anhydrous ethanol at room temperature. As the crystals begins to separate, the mixture was repeatedly subjected to heating $\left(<40{ }^{\circ} \mathrm{C}\right)$ and cooling $\left(\sim 20^{\circ} \mathrm{C}\right)$ for 5 days until about $30 \%$ of solvent ( $\sim$ ether $)$ was slowly evaporated. The precipitated crystals was filtered, washed with diethyl ether and dried furnished optically pure ethyl thiazolidine-2-carboxylate - L-TA as $78 \%$ yield. The remaining filtrate was heated and cooled for one more time to yield ethyl thiazolidine-2-carboxylate $\cdot \mathrm{L}-\mathrm{TA}$ as $12 \%$ yield (total 90\% yield, 99\% de).

The absolute configuration of optically pure ethyl thiazolidine-2-carboxylate $\cdot$ L-TA was determined by X-ray crystallo-

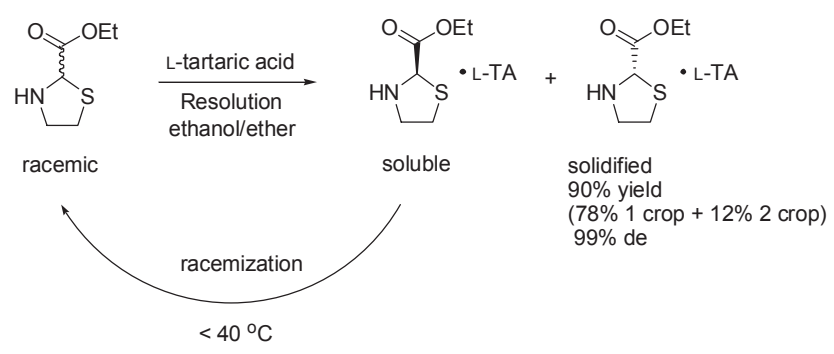

Scheme 1. Crystallization induced dynamic resolution of ethyl thiazolidine-2-carboxylate with L-tartaric acid

Table 2. Basification of (S)-ethyl thiazolidine-2-carboxylate - L-tartaric acid salt $(99 \%$ de)

\begin{tabular}{|c|c|c|c|c|c|}
\hline Entry & Base & Reaction time & Temperature & $\%$ ee & Yield \\
\hline 1 & $10 \% \mathrm{Na}_{2} \mathrm{CO}_{3}$ & $30 \mathrm{~min}$ & ice bath & 98 & $90 \%$ \\
\hline 2 & $10 \% \mathrm{Na}_{2} \mathrm{CO}_{3}$ & $3 \mathrm{~h}$ & $25^{\circ} \mathrm{C}$ & 82 & $92 \%$ \\
\hline 3 & $10 \% \mathrm{NaHCO}_{3}$ & $30 \mathrm{~min}$ & ice bath & $>99$ & $94 \%$ \\
\hline
\end{tabular}


Table 3. Racemization of (S)-ethyl-2-thiazolidine carboxylate

\begin{tabular}{ccccc} 
Condition & Time $(\mathrm{h})$ & $\begin{array}{c}(\text { S)-Ethyl-2-thiazolidine } \\
\text { carboxylate solvent free (solid) }\end{array}$ & $\begin{array}{c}(S) \text {-Ethyl-2-thiazolidine } \\
\text { carboxylate in ethanol }\end{array}$ & $\begin{array}{c}(S) \text {-Ethyl-2-thiazolidine } \\
\text { carboxylate in } \mathrm{CH}_{2} \mathrm{Cl}_{2}\end{array}$ \\
\hline $20{ }^{\circ} \mathrm{C}$ & 0 & $99 \%$ ee & $99 \%$ ee & $99 \%$ ee \\
$20{ }^{\circ} \mathrm{C}$ & 24 & $99 \%$ ee & $99 \%$ ee & $99 \%$ ee \\
$25{ }^{\circ} \mathrm{C}$ & 24 & & $99 \%$ ee \\
$30^{\circ} \mathrm{C}$ & 24 & $98 \%$ ee & $91 \%$ ee \\
$40^{\circ} \mathrm{C}$ & 24 & & $93 \%$ ee & \\
\hline
\end{tabular}

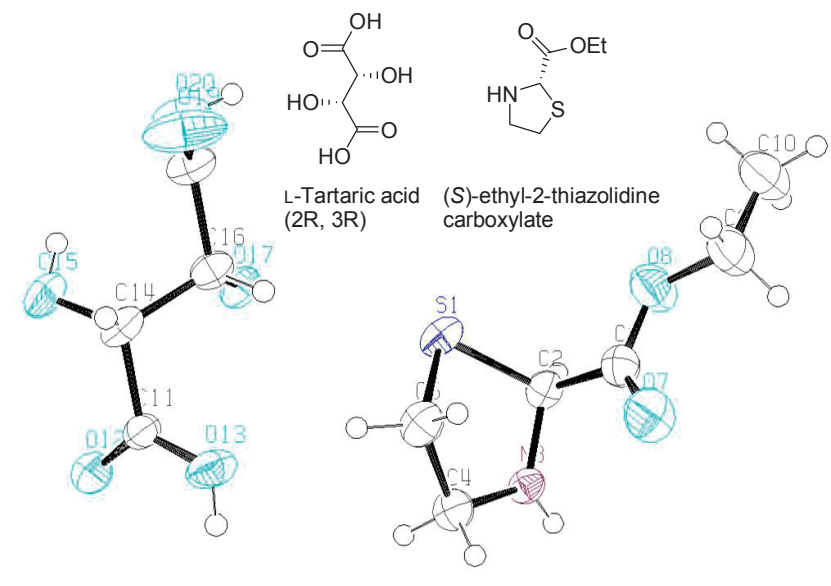

Figure 1. X-ray structure of $(S)$-ethyl thiazolidine-2-carboxylate - L-tartaric acid salt $(2 R, 3 R)$.

graphy. (S)-Ethyl thiazolidine-2-carboxylate was crystallized with L-tartaric acid salt (2R, 3R) as shown in Figure 1.

In order to obtain free form of (S)-ethyl thiazolidine-2-carboxylate, basification condition was optimized with weak bases as shown in Table 2. It was found that by stirring with $10 \%$ $\mathrm{NaHCO}_{3}$ in ice bath results excellent yield and \% ee of the (S)-ethyl thiazolidine-2-carboxylate.

Finally, we investigated the optical purity of $(S)$-ethyl thiazolidine-2-carboxylate under solvent free or in different solvent and at various temperatures as shown in Table 3 . We used $(S)$-ethyl thiazolidine-2-carboxylate with 99\% ee. Solvent free (solid, crystalline form) and solution of $(S)$-ethyl thiazolidine-2-carboxylate were stable below $20{ }^{\circ} \mathrm{C}$.

$(R)$-Ethyl thiazolidine-2-carboxylate was also obtained with the same procedure by using $(D)$-tartaric acid as a resolving agent.

In conclusion, crystallization induced dynamic resolution of racemic ethyl thiazolidine-2-carboxylate was described herein. Using CIDR, $(S)$-ethyl thiazolidine-2-carboxylate and L-tartaric acid salt (2R, 3R) was obtained in good yields (90\%) and \% de $(99 \%$ de). Also, absolute configuration of $(S)$-ethyl thiazolidine-2-carboxylate was determined by X-ray crystallography.

\section{Experimental}

(S)-Ethyl thiazolidine-2-carboxylate $\cdot$ L-tartaric acid (TA) salt.
To a stirred solution of L-tartaric acid (18.91 g, $0.126 \mathrm{~mol})$ dissolved in anhydrous ethanol $(103 \mathrm{~mL})$ was added racemic ethyl thiazolidine-2-carboxylate $(20.316 \mathrm{~g}, 0.126 \mathrm{~mol})$ dissolved in diethyl ether $(35 \mathrm{~mL})$ at room temperature. As the crystals begins to separate, the mixture was repeatedly subjected to heating and cooling for 5 days until about $30 \%$ of the reaction solvent was slowly evaporated. The precipitated crystals was filtered, washed with diethyl ether and dried furnished pure L-tartaric acid salt of $(S)$-ethyl thiazolidine-2-carboxylate as white solid (31.38 g, 78\%). The remaining filtrate was heated and cooled for one more time to yield ethyl thiazolidine-2carboxylate $\cdot$ L-TA as white solid (4.83 g, 12\%) (total 90\% yield, 99\% de); mp $115-117^{\circ} \mathrm{C}$.

(S)-Ethyl thiazolidine-2-carboxylate. $(S)$-Ethyl thiazolidine2-carboxylate $\cdot \mathrm{L}$-TA salt $(16.55 \mathrm{~g}, 50 \mathrm{mmol})$ was added in $10 \%$ sodium bicarbonate solution $(\sim 500 \mathrm{~mL})$ and the mixture was stirred at $10{ }^{\circ} \mathrm{C}$ or less, for $30 \mathrm{~min}$. The reaction mixture was extracted with diethyl ether $(3 \times 100 \mathrm{~mL})$ and washed with distilled water. The combined organic layer was dried over anhydrous $\mathrm{MgSO}_{4}$, filtered and concentrated to furnish $(S)$-ethyl thiazolidine-2-carboxylate $(7.32 \mathrm{~g}, 94 \%)$.

${ }^{1} \mathrm{H}$ NMR $\left(300 \mathrm{MHz}, \mathrm{CDCl}_{3}\right) \delta 4.93$ (brs, $\left.1 \mathrm{H}\right), 4.26$ (q, $J=$ 7.1 Hz, 2H), 3.72-3.63 (m, 1H), 3.13-2.98 (m, 2H), 2.90-2.81 (m, 1H), 2.33 (br, 1H), 1.32 (t, $J=7.1 \mathrm{~Hz}, 3 \mathrm{H})$.

HPLC: Daicel OD column 4.6*250 mm, EtOH $/ n$-Hexane (1/9) with $0.1 \%$ diethylamine, $1.0 \mathrm{~mL} / \mathrm{min}, 254 \mathrm{~nm} \mathrm{UV}$ detector; $(S)$-Ethyl thiazolidine-2-carboxylate, $6.5 \mathrm{~min}),(R$-form, 7.4 $\min )$; $\operatorname{mp} 27-29{ }^{\circ} \mathrm{C}$.

Acknowledgments. This research was supported by the Center for Biological Modulators of the 21st Century Frontier R\&D Program, Ministry of Education, Science and Technology, Korea.

\section{References}

1. Johnson, R. L.; Smissman, E. E.; Plolnikoff, N. P. J. Med. Chem. 1978, 21, 165-169.

2. Lalezari, I.; Schwarta, L. J. Med. Chem. 1988, 31, 1427-1429.

3. Karanewsky, D. S.; Badia, M. C.; Cushman, D. W.; DeForrest, J. M.; Dejneka, T.; Lee, V. G. Loots, M. J.; Petrillo, E. W. J. Med. Chem. 1990, 33, 1459-1469.

4. Lange, E. W.; Baucke, D.; Hornberger, W.; Mack, H.; Seitzb, W.; Höffken, H. W. Bioorg. Med. Chem. Lett. 2006, 16, 2648-2653.

5. Shiraiwa, T.; Katayama, T.; Kaito, T.; Tanigawa, H.; Kurokawa, H. Bull. Chem. Soc. Jpn. 1998, 71, 1911-1914. 
6. Refouvelet, J. B.; Robert, J. B.; Couquelet, J. B.; Tronche, P. J. J. Heterocycl. Chem. 1994, 31, 77-80.

7. Baker, P. W.; Bais, R. B.; Roff, A. M. Biochem. J. 1994, 302, 753757.

8. Shiraiwa, T.; Katayama, T.; Ishikawa, J.; Takeshi, A.; Kurokawa, H. Chem. Pharm. Bull. 1999, 47, 1180-1183.

9. (a) Caddick, S.; Jenkins, K. Tetrahedron Lett. 1996, 37, 1301. (b)
Kolarovic, A.; Berkes, D.; Baran, P.; Povazanec, F. Tetrahedron Lett. 2001, 42, 2579. (c) Shieh, W.-C.; Carlson, J. A.; Zaunius, G. M. J. Org. Chem. 1997, 62, 8271. (d) Vedejs, E.; Fields, S. C.; Hayashi, R.; Hitchcock, S. R.; Powell, D. R.; Schrimpf, M. R. J. Am. Chem. Soc.1999, 121, 2460.

10. Striegel, H.-G.; Laufer, S.; Tollmann, K.; Tries, S. US patent 2003/ 0153558; 2003. 